\title{
Effect of TSPO Ligand, Ro5-4864, on Lung Injury in ARDS Model Induced by ANTU in Rats
} \author{
Can $^{5 *}$, \\ ${ }^{1}$ Department of Pharmacology, Bulent Ecevit University, Turkey \\ ${ }^{2}$ Department of Pathology, Atilim University, Turkey \\ ${ }^{3}$ Department of Immunology, Bulent Ecevit University, Turkey \\ ${ }^{4}$ Department of Biostatistics, Bulent Ecevit University, Turkey \\ ${ }^{5}$ Department of Medical Pharmacology, Bulent Ecevit University, Turkey
}

Billur Dereli' ${ }^{1}$, Gamze Yurdakan², Ishak Ozel Tekin ${ }^{3}$, Mehmet Arasli³ ${ }^{3}$ Firuzan Kokturk ${ }^{4}$, and Emine Yilmaz-

Submission: October 13, 2021; Published: October 28, 2021

*Corresponding author: Emine Yilmaz Can, MD, Zonguldak Bulent Ecevit University, Faculty of Medicine, Department of Medical Pharmacology, 67600 Kozlu, Zonguldak, Turkey

\begin{abstract}
Background: Acute respiratory distress syndrome (ARDS) is associated with high morbidity and mortality. Despite intensive research, pharmacological treatments remain limited and only supportive therapies represent the mainstay of treatment of ARDS. In recent years, evidence has been published showing that benzodiazepine ligands can be protective and therapeutic against tissue damage. The aim of the present study was to investigate for the first time the role of selective peripheral benzodiazepine receptors (TSPO) expression, apoptosis/necrosis development process and cytokine levels in ANTU induced ARDS model in rats.
\end{abstract}

Materials and Methods: ARDS model was created by intraperitoneal (i.p.) injection of $\alpha$ naphthylthiourea (ANTU). Selective peripheral benzodiazepine receptor ligand, Ro5-4864, was administered to rats intraperitoneally $30 \mathrm{~min}$ prior to ANTU (2 and $4 \mathrm{mg} / \mathrm{kg}$ ). 4 hours after ANTU, blood and lung tissue samples were collected. Histopathologic state, peripheral benzodiazepine receptors (PBRs), tumor necrosis factor alpha (TNF- $\alpha$ ), caspase-3 and inducible nitric oxide synthase (iNOS) enzyme expressions, and serum cytokine levels (interleukin 1alpha (IL-1), interferon gama (IFN- $\gamma$ ), monocyte chemotactic protein-1 (MCP-1), and interleukin 4 (IL-4) were evaluated. Annexin V method was used for flow cytometric detection of phosphatidylserine expression on lung cells undergoing apoptosis.

Results: Ro5-4864 showed dose-dependent and significant protective effect on inflammation, hemorrhage, pulmonary edema and pleural effusion induced by ANTU. Ro5-4864 significantly reduced PBR, caspase-3 and TNF expressions and serum MCP-1 levels. Ro5-4864 also showed a significant protective effect against ANTU induced necrosis in rat lung tissue.

Conclusion: In this study, the possible effects of Ro5-4864 on PBR expression and apoptosis/necrosis development process were investigated for the first time in ANTU induced ARDS model in rats. It was shown for the first time that PBR expression increases in ANTUmediated lung injury and plays a role in the pathological process. Selective peripheral benzodiazepine receptor agonist displayed a protective effect on pulmonary edema, effusion development and apoptosis/necrosis process. These results suggest that benzodiazepines may display protective effect over the lung damage mechanisms through their peripheral receptors located at periphery as different from those located at central nervous system. This positive and protective effect of peripheral benzodiazepine receptors on lung tissue damage and inflammation may enable them to be used as potential medication in lung diseases.

Keywords: Acute respiratory distress syndrome; $\alpha$-Naphthylthiourea; 4' chlorodiazepam (Ro5-4864); Pulmonary edema; Pleural effusion

Abbreviations: ARDS: Acute Respiratory Distress Syndrome; ANTU: $\alpha$-Naphthylthiourea; BZ: Benzodiazepine; IP: Intraperitoneal; INOS: Inducible Nitric Oxide Synthase; TNF- $\alpha$ : Tumor Necrosis Factor Alpha; IL-1 $\alpha$ : Interleukin 1Alpha; IFN- $\gamma$ : Interferon Gama; MCP-1: Monocyte Chemotactic Protein-1; IL-4: Interleukin 4; LW/BW: Lung Weight/Body Weight; PE/BW: Pleural Effusion/Body Weight; GABA: $\gamma$-Aminobutyric Acid; PBR: Peripheral Type Benzodiazepine Receptors; TSPO: Translocator Protein; CLP: Cecal Ligation and Puncture; LPS: Lipopolysaccharide; I/R: Ischemia/Reperfusion; PBS: Phosphate-buffered Saline; NO: Nitric Oxide; IL-2 : Interleukin 4; IL-6: Interleukin 6; L-NAME: NG-Nitro-LArginine Methyl Ester; IL-8: Interleukin-8; FITC: Fluorescent Isothiocyanate; ALI: Acute Lung Injury

\section{Introduction}

Acute respiratory distress syndrome (ARDS) is still among the deadliest disease with a high mortality rate, despite the fact that it has been four decades since its definition and new treatment opportunities brought by technology [1]. ARDS is triggered by 
many different causes that cause damage to the lung [2]. It is a non-cardiac pulmonary edema that starts acutely and leads serious structural changes including inflammation, proliferation and fibrosis in the lungs [1]. Today, ARDS treatment has not gone beyond the symptomatic approach and pharmacotherapy has not passed the experimental stage. This treatment failure in ARDS is being tried to be solved by intensive experimental studies. The difficulty of clinical studies on this subject reveals the importance of experimental studies.

Benzodiazepine (BZ) derivatives interact with different central and peripheral type receptors; therefore they have wide usage areas such as tranquilizing, antidepressant, muscle relaxant, anticonvulsant, sedative, analgesic, anti-inflammatory and anxiolytic effects. Benzodiazepines exert their pharmacological effects by binding to their specific BZ binding sites (or BZ receptors) on the $\gamma$-aminobutyric acid (GABA) receptor [3]. In addition to central type receptors in the brain, benzodiazepines have been shown to have peripheral type receptors (PBR) in some organs and cells outside the brain $[4,5]$. The PBR is distinct from the central benzodiazepine receptor in its molecular structure, pharmacology, anatomical distribution, subcellular localization, and physiological function [6].

Studies indicate that PBRs are present in various organs throughout the body, including heart, kidney, liver, lung, adrenal gland, and intestine [6], and cells, including platelets, erythrocytes, lymphocytes, mononuclear cells, endothelium, vascular smooth muscle, and mast cells [7]. The subcellular location of PBR is primarily in mitochondria. Classical synthetic ligands of PBR are PK 11195 and Ro5 4864. It is stated that PBR functions include steroidogenesis, apoptosis, cell proliferation, mitochondrial membrane potential, mitochondrial respiratory chain, voltagedependent calcium channels, stress response and regulation of microglial activation.

It has been suggested that PBRs in blood cells play a role in various aspects of the immune response, such as phagocytosis and secretion of interleukin-2, interleukin-3 and immunoglobulin A $[7,8]$. The PBR was renamed $18 \mathrm{kDa}$ Translocator Protein (TSPO) in 2006 by the HUGO Gene Naming Board, reflecting its putative function in protein or ligand transport/translocation [9]. Further studies have shown that TSPOs are found in both brain and peripheral tissues. We have recently found that Ro5-4864 could be effective in reducing epidural fibrosis in an experimental study model (post-laminectomy) in rats [10]. Our data revealed that epidural fibrosis was significantly reduced in rats treated with Ro5-4864 compared to the control and saline-soaked spongostan groups.

Pulmonary system has high TSPO densities in submucosal glands, epithelium, ductal smooth muscle [4], and type II alveolar cells [5]. It has been suggested that PBRs could be involved in broncho motor tonus modulation and respiratory system function. Recent studies have shown that TSPOs play a role in regulation of immune function and inflammation in the pulmonary system, including carrageenan-induced pleurisy and pleural exudation in mice [6,7], and immune disorder-induced alveolitis [8] but there are no reports of the role of TSPO ligand Ro5-4864, on TSPO expression and apoptosis/necrosis development process, and TNF- $\alpha$, IL- $1 \alpha$, IFN- $\gamma$, MCP-1, IL-4 levels in ANTU model of ARDS in rats. This study was designed to investigate for the first time the effects of the selective peripheral benzodiazepine receptor agonist Ro5-4864 on the above-mentioned mechanisms.

\section{Materials and Methods}

\section{Animals}

Adult male Wistar Albino rats weighing 200-240g were used in this study, which was obtained from the animal laboratory of Zonguldak Bulent Ecevit University. They were kept under controlled conditions (at temperature of $22 \pm 2^{\circ} \mathrm{C}$ and $12 \mathrm{~h}$ lightdark cycles) and were fed with rat chow diet and tap water. Rats were fasted prior to operation and were allowed just free access to water. The experimental protocols were confirmed by the Bulent Ecevit University of Ethical Committee of Experimental Animals. During the experimental procedures, the animals were placed in separate cages and the laboratory conditions were maintained at room temperature $\left(22^{\circ} \mathrm{C}\right)$. The procedures and protocols of the study were in accord with our institutional guidelines, which are consistent with those of the "Guide for the Care and Use of Laboratory Animals" (US National Institute of Health, revised 1985).

\section{Experimental groups}

Fourty rats were designed into four groups each containing 10 animals (Table 1): 1) Control group, 2) ANTU group, 3) Selective peripheral benzodiazepine receptor agonist Ro5-4864 2mg/kg treatment group, 4) Selective peripheral benzodiazepine receptor agonist Ro5-4864 4mg/kg treatment group.

\section{Experimental protocol}

\section{$\alpha$-Naphthylthiourea administration}

During the experiment, the animals were placed in separate cages and kept at room temperature $\left(22^{\circ} \mathrm{C}\right)$. ANTU (suspended in olive oil at $4 \mathrm{mg} / \mathrm{ml}$ ) was injected intraperitoneally (i.p.) at a dose of $10 \mathrm{mg} / \mathrm{kg}$. When injected into rats, ANTU produces pulmonary edema, as indicated by an increase in the lung weight/body weight ratio (LW/BW) and pleural effusion (PE), reaching a maximum within $4 \mathrm{~h}$. The solvent control group received the same volume of olive oil alone. Then $4 \mathrm{~h}$ later, the animals were anesthetized with thiopental sodium ( $50 \mathrm{mg} / \mathrm{kg}$ i.p.), Blood samples were taken from the abdominal aorta. Serum samples were separated by centrifugation and kept at $-80^{\circ} \mathrm{C}$ until the time of measurement. The thorax was opened, and any PE was collected carefully by suction and measured volumetrically. Care was also taken to avoid blood contamination of the PE. 
Table 1: Experimental Groups $(n=10)$.

\begin{tabular}{|c|c|c|}
\hline \multicolumn{1}{|c|}{ Groups } & Chemicals \\
\hline 1 & Control (olive oil) \\
\hline 2 & A.p. & ANTU group $(10 \mathrm{mg} / \mathrm{kg})$ \\
\hline 3 & A.p. & ANTU+ Ro 5-4864 $(2 \mathrm{mg} / \mathrm{kg})^{\mathrm{a}}$ \\
\hline 4 & i.p./i.p. \\
\hline
\end{tabular}

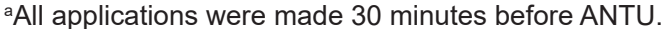

The lungs were removed and all surrounding tissues were dissected and weighed with an analytical balance and used for histological examination. The volume of PE (mL) and the LW/ BW and pleural effusion /body weight (PE/BW) ratios were calculated and used as indices of ARDS. The left lobe of the lung was preserved in formaldehyde for histopathological examination. The right lobe of the lung was used as a fresh tissue for apoptosis / necrosis study immediately after washing with cold saline. In order to achieve standardization between animals, lung weight and pleural effusion were examined by proportion to body weight. The amount of effusion fluid (PE, ml), lung weight / body weight (LW/BW) and pleural effusion / body weight (PE/BW) ratios were calculated and evaluated as indicators of acute lung injury (ALI). INOS, TNF-alpha, peripheral benzodiazepine receptor, caspase-3 immunohistochemical examination studies were performed in lung tissues.

\section{Light microscopic procedures}

For the histological examination, the lung tissue samples were fixed in \%10 formalin immediately after removal, dehydrated in graded concentrations of ethanol, cleared in xylene, and embedded in paraffin. All lung lobes were used for the histological examination. At least eight tissue section 3-5 $\mu \mathrm{m}$ thick, were obtained and then stained with hematoxylin and eosin. A pathologist performed a blind examination of the sections under a light microscope. All pathological changes were documented in each lung tissue sample, including intra-alveolar hemorrhage, alveolar edema and inflammation.

Alveolar edema (swelling of the alveolar wall) and intra alveolar hemorrhage were scored on a scale of $0-3$, with 0 indicating the absence of pathologic features $(<\% 5$ of maximum pathologic features); 1 , mild $(\%<10) ; 2$, moderate $(\% 15-20)$; and 3 , severe (\%20-25) [11]. Leukocyte infiltration was evaluated to determinate the severity of the alveolar inflammation. Each section was divided into 10 subsections, and leukocyte infiltration was examined in each of the subsections at a magnification of $400 x$ using the following scale: 0 , no extravascular leukocytes; 1, <10 leukocytes; $2,10-45$ leukocytes, or 3, >45 leukocytes. The average of the data was used for comparison [12].

\section{Immunohistochemical analysis}

iNOS, TNF-alpha, peripheral benzodiazepine receptor, caspase-3 immunohistochemical staining studies were performed in the lung tissue. Immunohistochemical study was performed on formalin-fixed paraffin-embedded tissues using the streptavidinbiotin technique. Sections with a thickness of 4 microns were deparaffinized and then dehydrated with ethanol and xylene. Endogenous peroxidase activity was blocked with methanol containing $0.3 \%$ hydrogen peroxide for 30 minutes.

After pre-stages were applied in $10 \mathrm{mM}$ pH 6.0 citrate buffer for iNOS and caspase 3, pepsin for peripheral type benzodiazepine receptor and sodium citrate buffer for TNF alpha, nonimmunized sections were incubated with primary antibodies for 10 minutes with PBS. As the primary antibody; anti-Nitric oxide synthase, inducible (anti-iNOS) (Lab Vision Corporation, Fremont, CA, USA 1:200 dilution, anti-Caspase 3 (CCP32) (Lab Vision Corporation, Fremont, CA, USA 1:200 dilution, anti-Peripheraltype Benzodiazepine Receptor (BioVision Incorporated, Milpitas, CA, USA at 1:200 dilution and Anti-TNF alpha antibody (ab66579) (abcam Incorporated, Cambridge, UK) at 1:2000 dilution Ultravision Large Volume Detection System (Thermo Scientific) Lab Vision Corporation Fremont, CA, USA).

\section{Determination of cytokines in serum}

Blood samples were taken from the abdominal aorta. Serum samples were separated by centrifugation and kept at $-80^{\circ} \mathrm{C}$ until the time of measurement. Measurement of IL- $1 \alpha$, TNF- $\alpha$, IFN- $\gamma$ and MCP-1 levels in rat serum was performed using fluorescent bead immunoassay method and Flow Cytomix Multiple Analyte Detection Rat Cytokine 6plex kit (eBioscience Bender Med Systems $\mathrm{GmbH}$, Vienna, Austria). Measurements were made on the basis of the kit's user manual. In summary, fluorescent beads coated with monoclonal antibodies specific for different cytokines and chemokines, and monoclonal antibodies conjugated with cytokine and chemokine specific biotin were suspended together with serum samples or serial diluted standards. 
After 2 hours of incubation, the beads were washed twice and incubated with Streptavidin-phytoerythrin solution for 1 hour. After the repeated washing procedure, the samples became available for flow cytometry analysis. Forward and side scatter voltages adjusted; A $675 \mathrm{~nm}$ (fluorescent 4) detector was used to show bead differentiation, and a $575 \mathrm{~nm}$ (fluorescent 2) detector was used for bead measurement. The standard curve range was determined as indicated for each cytokine and chemokine: $0-20,000 \mathrm{pg} / \mathrm{ml}$ for IL- $1 \alpha$, and TNF- $\alpha, 0-5,000 \mathrm{pg} / \mathrm{ml}$ for MCP1 , and $0-0$ for IFN- $\gamma 2,000 \mathrm{pg} / \mathrm{ml}$. Measurements were made using Beckman Coulter Cytomics FC500 flow cytometry device in the samples. 3000 beads were collected for each analysis. Concentration values were calculated from respective standards using the Flow Cytomix Pro 3.0 program (e-Bioscience Bender MedSystems GmbH, Vienna, Austria).

\section{Evaluation of apoptosis by flow cytometry}

The basis of the apoptosis evaluation method by flow cytometry is based on measuring the affinity of annexin $\mathrm{V}$ to phosphatidylserine, which is translocated from the inner surface of the cell membrane to the outer surface of the cell membrane in cells undergoing apoptosis. The study was performed on fresh right lung tissue. The right lung lobes were used for the apoptosis/ necrosis study immediately after washing with cold saline. First, cells from lung tissue were collected separately. $100 \mu$ of cell suspension was used for each sample.

Cells were stained with annexin V-coated fluorescent isothiocyanate (FITC) in the presence of propidium iodide (PI). This application enables the determination of phosphatidylserine on the surface of apoptotic cells. Both PI and annexin V positive cells show necrosis (\%). In the study, annexin-FITC kit (BeckmanCoulter, Fullerton, CA, USA) was used in accordance with the instructions for use and measurements were made on the Coulter
FC500 TM flow cytometer (Beckman-Coulter).

\section{Statistical analyses}

Results are expressed as means \pm standard error of the mean (SEM). Comparisons between groups were made using one way ANOVA, followed in cases of significance by an LSD test. P values $<0.05$ were considered to indicate statistical significance. Statistical analyses were performed using the SPSS software (ver. 13.0 for Windows; SPSS Inc., Chicago, IL, USA).

\section{Chemicals}

Ro5-4864 from Sigma-Aldrich (St. Louis, MO, USA) was dissolved in absolute ethanol and diluted with phosphate-buffered saline to the appropriate concentration. Olive oil was purchased from Sigma. $\alpha$-Naphthylthiourea (Interchim) was suspended in olive oil $(4 \mathrm{mg} / \mathrm{mL})$ and was a gift from Dr. E. Schillinger, Schering AG, Berlin, Germany.

\section{Results}

\section{Effect of ANTU and Ro5-4864 on pulmonary tissue}

In the histopathological examination, ANTU, used as an ARDS model, was found to cause intense and widespread leukocyte infiltration in the lung tissue, moderate alveolar edema and intra alveolar hemorrhage (Figure1). It was found that Ro5-4864 had a protective effect on inflammation in both doses in the ANTU group, while it significantly reduced hemorrhage only at a dose of $2 \mathrm{mg} / \mathrm{kg}$ (Figure 1$)$. A statistically significant increase $(\mathrm{p}<0.05)$ was found in the LW/BW ratios compared to the control group, 4 hours after the administration of ANTU. Selective peripheral benzodiazepine receptor agonist Ro5-4864, at doses of 2 and $4 \mathrm{mg} / \mathrm{kg}$, caused a reduction in lung weight/body weight (LW/ BW) ratios, this reduction was statistically significant only at the $2 \mathrm{mg} / \mathrm{kg}$ dose (Figure 2, Table 2).

Table 2: LW/BW, PE/BW ratios and PE amounts of all groups.

\begin{tabular}{|c|c|c|c|}
\hline Groups & $\begin{array}{c}\text { Lung Weight/Body Weight Ratio (LW/ } \\
\text { BW x 10 } \mathbf{~}^{4}\end{array}$ & $\begin{array}{c}\text { Pleural Effusion/Body Weight Ratio } \\
\text { (PE/BW x 10 }\end{array}$ & $\begin{array}{c}\text { Amount of Pleural Effusion } \\
\text { (PE, ml) }\end{array}$ \\
\hline Control & $47.2 \pm 2.3$ & 0 & 0 \\
\hline ANTU & $91.1 \pm 8.2^{\#}$ & $142.7 \pm 10.4^{\#}$ & $3.9 \pm 0.3^{\#}$ \\
\hline $\begin{array}{c}\text { ANTU + Ro5-4864 } \\
(2 \mathrm{mg} / \mathrm{kg})\end{array}$ & $76.6 \pm 2.9^{*}$ & $90.6 \pm 9.3^{*}$ & $2.3 \pm 0.2^{*}$ \\
\hline $\begin{array}{c}\text { ANTU }+ \text { Ro5-4864 } \\
(4 \mathrm{mg} / \mathrm{kg})\end{array}$ & $82.4 \pm 2.4$ & $43.1 \pm 9.9^{*}$ & $0.96 \pm 0.2^{*}$ \\
\hline
\end{tabular}

${ }^{\#} p<0.05$ Significant compared to the control group; " $\mathrm{P}<0.05$ Significant compared to ANTU group. 


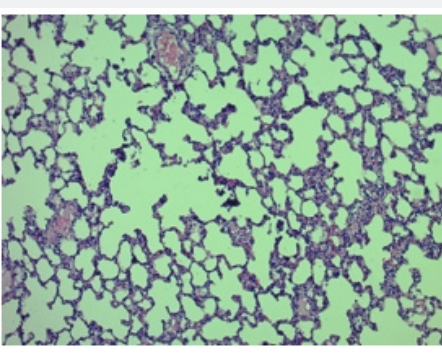

A1. Control Rat Lung X10H\&E

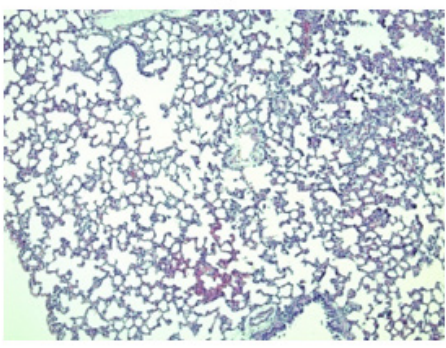

B1. ANTU + RO (2mg/kg) Rat Lung X10H\&E

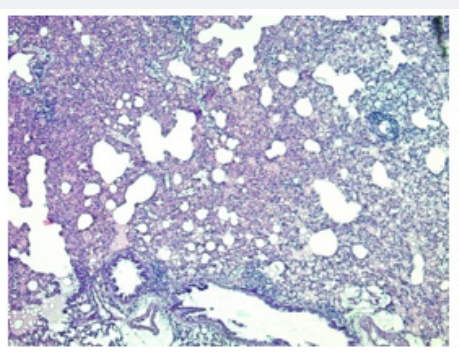

A2. ANTU Rat Lung X10H\&E

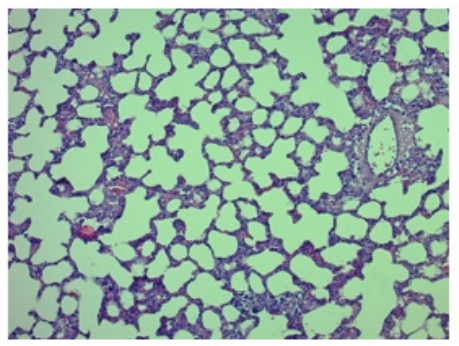

B2. ANTU + RO (4mg/kg) Rat Lung X10H\&E

Figure 1: H-E staining of control, ANTU and Ro5-4864 groups. A1)Control, A2)ANTU, B1)ANTU+2mg/kg Ro5-4864, B1) ANTU+4mg/kg Ro5-4864.

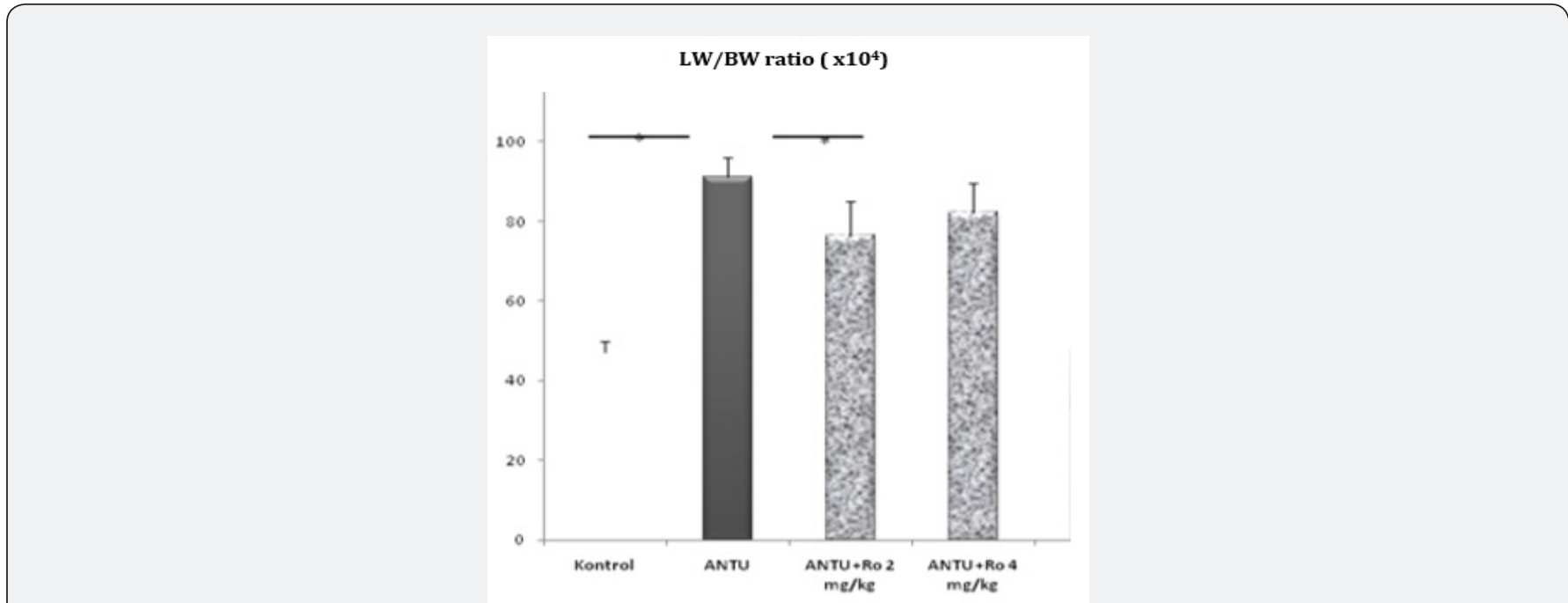

Figure 2: The effects of Ro5-4864 on lung weight/body weight ratio (LW/BW x104) in ANTU-induced lung injury. $n=10$ in each group, ${ }^{*} \mathrm{p}<0.05$.

No pleural effusion was detected in the lungs of healthy control group rats. Non-hemorrhagic pleural effusion development was observed in ANTU group. A statistically significant higher amount of effusion development was detected in the ANTU group when compared to the control group $(\mathrm{p}<0.05)$ (Figure 3,4 Table 2). There was a statistically significant decrease in the amount of effusion in both doses of Ro5-4864. Ro5-4864 provided protection against development of effusion due to ANTU. It was found that PBR and TNF expressions were significantly reduced in both doses of Ro54864 , while it reduced caspase- 3 staining only at the dose of $2 \mathrm{mg} /$ kg (Figure 5) in immunohistochemical analyzes.

It was observed that Ro5-4864 did not have a significant protective effect on iNOS expression. MCP-1 levels increased in the ANTU group, and this increase was statistically significantly reduced with 2 and $4 \mathrm{mg} / \mathrm{kg}$ doses of Ro5-4864. IL-1, IL-4 and IFN- $\gamma$ levels did not differ between groups in serum samples. When the groups were evaluated in terms of apoptosis, it was observed that a significant rate of necrosis was observed in the ANTU group, and Ro5-4864 showed significantly protection against this condition at the doses of 2 and $4 \mathrm{mg} / \mathrm{kg}$. 


\section{PE/BW ratio $\left(\mathrm{x} 10^{4}\right)$}

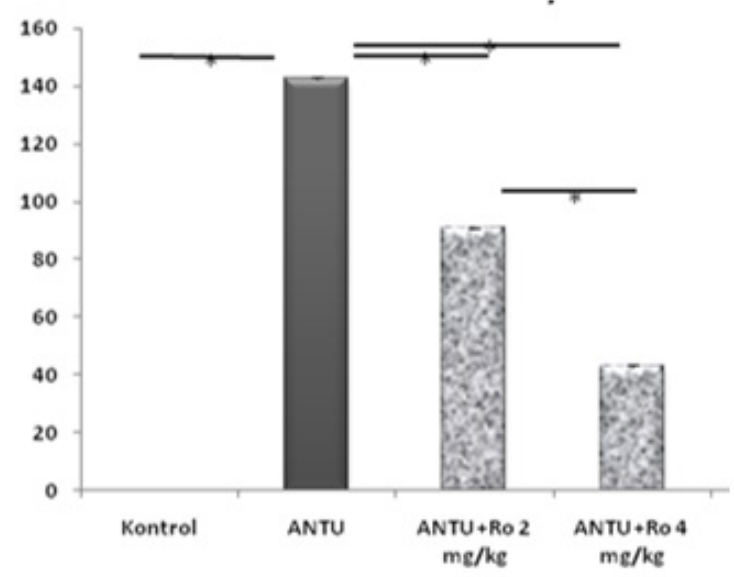

Figure 3: Effects of Ro5-4864 on pleural effusion/body weight ratio (PE/BW x 104) in ANTU-induced lung injury. $n=10$ in each group, ${ }^{*} p<0.05$

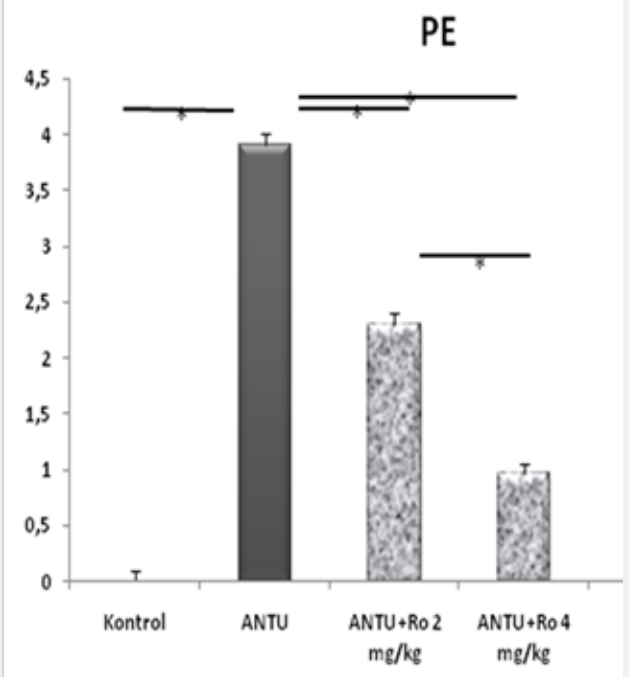

Figure 4: The effects of Ro5-4864 on the amount of pleural effusion (PE) (ml) in ANTU induced lung injury. $n=10$ in each group, ${ }^{*} p<0.05$.

\section{Discussion}

In this study, the effects of Ro5-4864 on the apoptosis/ necrosis development process, TSPO and iNOS expressions and TNF- $\alpha$, IL- $1 \alpha$, IFN- $\gamma$, MCP-1, IL-4 levels were investigated for the first time in the ARDS model induced by ANTU. It was shown for the first time that TSPO expression increases in ANTU-mediated lung injury and plays a role in the pathological process. Selective peripheral benzodiazepine receptor agonist showed a protective effect on pulmonary edema, effusion development and apoptosis/ necrosis process. These results suggest that benzodiazepines may exert a protective effect on lung injury mechanisms through peripheral receptors located in the periphery, unlike those in the central nervous system. Our study results are compatible with the literature that peripherally located benzodiazepine receptors can have a positive and protective effect on tissue damage and inflammation.

On the other hand, there are not enough studies examining the place and effects of PBRs in the respiratory system $[13,14]$. ARDS is a syndrome due to increased permeability and noncardiogenic pulmonary edema [15] and is a major cause of morbidity and death in intensive care units. In ARDS, alveolar edema accumulates mainly due to the increase in the permeability of the capillary (endothelial)-alveolar (epithelial) barrier. The American-European consensus conference on ARDS defined ARDS as a "syndrome of inflammation and increased permeability" [16, 17]. Therefore, it is accepted that the pathophysiology of ARDS 
is caused by a severe inflammatory reaction that damages the alveolar-capillary structure $[18,19]$. Our study data also show that peripheral benzodiazepine receptors may be protective through similar mechanisms in ANTU-mediated ARDS pathological processes. On the other hand, the exact mechanisms of lung injury, time course, inflammatory pathways, and cell repair processes are not well understood in ARDS [20].

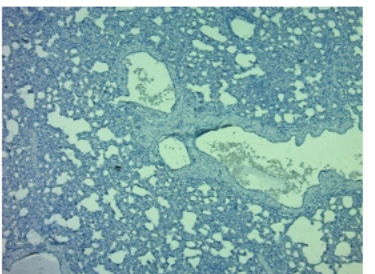

A1. Control Rat Lung TNF- $\alpha$ X5

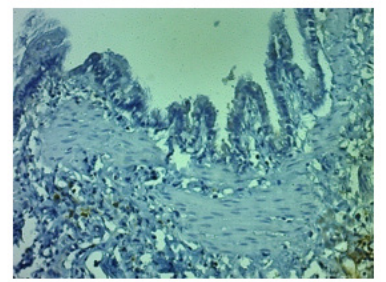

B1. ANTU+RO (2mg/kg) TNF- $\alpha$ Rat Lung X20

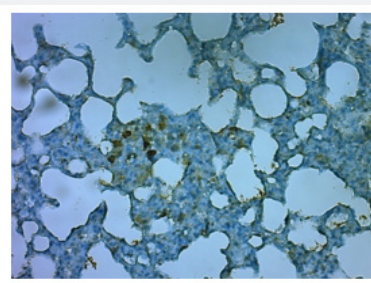

C1. Control Rat Lung Caspase-3 340

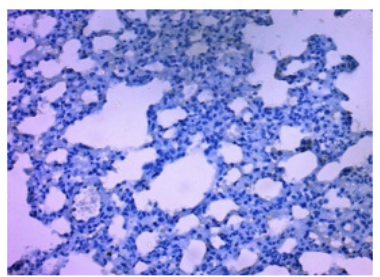

D1. ANTU+Ro (2mg/kg) Caspase-3 Rat Lung X20

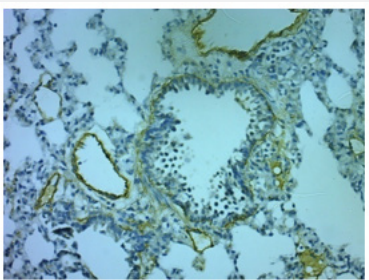

E1. Control Rat Lung PBR X20

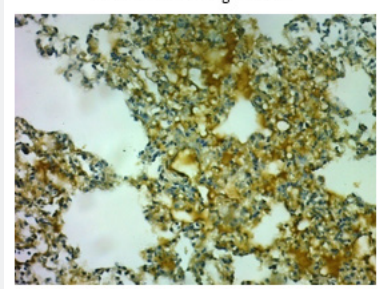

F1. ANTU+RO (2mg/kg) PBR Rat Lung X20

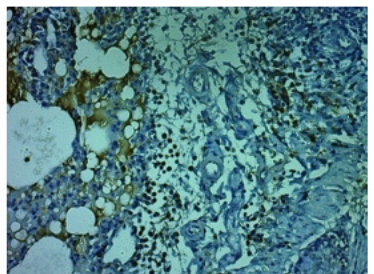

A2. ANTU Rat Lung TNF- $\alpha$ X20

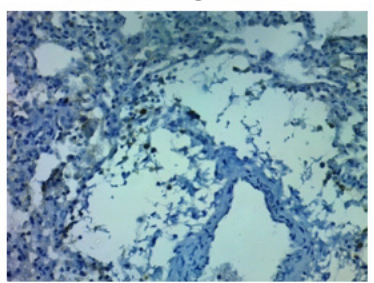

B2. ANTU+RO (4mg/kg) TNF- $\alpha$ Rat Lung X20

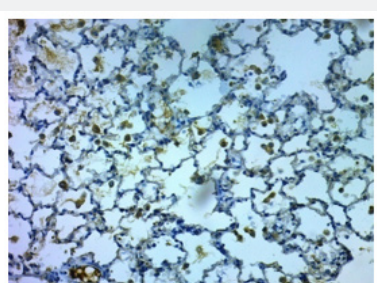

C2. ANTU Rat Lung Caspase- 3 X20

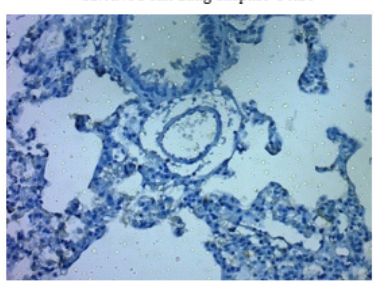

D2. ANTU+RO (4mg/kg) Caspase-3 Rat Lung X20

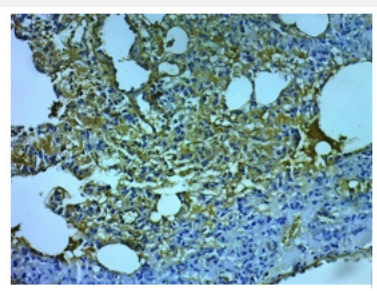

E2. ANTU Rat Lung PBR X20

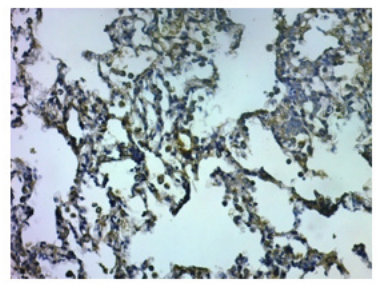

F2. ANTU+RO (4mg/kg) PBR Rat Lung X20

Figure 5: Immunohistochemical staining of control, ANTU and Ro5-486 groups. A/B)TNF stainings, C/D)Caspase-3 stainings, E/F) PBR stainings. 
In our study, the possible effects of TSPOs on apoptosis/ necrosis were investigated for the first time in ARDS model induced by ANTU. ANTU is one of the agents used to develop ARDS experimental model. ANTU is a chemical agent which developed as rodenticide, leading death by pulmonary failure by pulmonary edema and pleural effusion. Studies have shown that it develops acute lung injury in a dose and time dependent manner. ANTU has been shown to take capillary endothelial cells as the target structure in the lung injury mechanism [21]. On the other hand, the mechanism of action of ANTU has not been clearly elucidated, but it is thought that the pathogenesis of pulmonary edema due to ANTU is mediated by some vasoactive substances thought to originate from the pulmonary vascular bed and airway. Studies have shown that many mediators of inflammation and tissue damage such as L-arginine/NO pathway, endothelin and angiotensin peptides, eicosanoids, reactive oxygen radicals, lipid peroxidation and oxidized DDL play a role in ANTU-mediated ARDS [22-30].

ANTU induced damage has been shown to be mediated partially through arachidonic acid metabolites [31]. After i.v. injection of radiolabeled ANTU, it causes covalent binding to macromolecules in the lung, and these toxic compounds produce reactive molecules [32]. Furthermore, we have shown for the first time the roles of endothelin peptides [26], the L-arginine/nitric oxide (NO) pathway [21,30], lipid peroxidation [33], in ANTUinduced ARDS. Additionally, we showed that morphine [30], pentobarbital, thiopental, urethane [34], and dexmedetomidine [35] have preventative effects on ANTU induced ARDS. Our results support our previous findings in 4 different ARDS models regarding the protective effects of Ro5-4864 on lung injury [36]. In that study, we have recently shown the proflactic effects of TSPO ligand on experimental ARDS models induced by lipopolysaccharide (LPS), cecal ligation and puncture (CLP), mesenteric ischemia/reperfusion (I/R) and ANTU.

In ANTU group of that study, only histopathological examination (hematoxylin and eosin analyzes with light microscope) was performed. On the other hand, in our current study, the mechanism of the ANTU-mediated protective effect was examined in detail for the first time mainly in terms of peripheral benzodiazepine receptor expression and apoptosis/ necrosis processes. The exact mechanism of pulmonary edema and PE formation observed in ANTU-mediated injury is unclear, but we suggest in current study that acute inhibitory effect of Ro5-4864 on fluid accumulation was more effective in the pleural cavity than the interstitial compartment in this model of ARDS. Although a reduction in pleural effusion was observed at all doses, the protective effect (LW/BW ratio) of Ro5-4864 against intra alveolar edema was observed only at a dose of $2 \mathrm{mg} / \mathrm{kg}$. This is an important ARDS model that also provides the opportunity to examine the effects of Ro5-4864 on pleural effusion.

Because ARDS is defined as a syndrome of inflammation and increased permeability, we suggest that PBR is involved in the pulmonary inflammatory response. Our results may support earlier findings concerning the anti-inflammatory effects of Ro54864. After Ro5-4864 treatment, there was no mortality within $4 \mathrm{~h}$ in ANTU group. This indicates that Ro5 4864 has a protective effect against mortality and may contribute to a decrease in mortality rates in intensive care units. Benzodiazepines bind to GABAA receptors in the central nervous system as well as other sites in peripheral tissues. These receptors located on the mitochondrial outer membrane of various cells are called peripheral type benzodiazepine receptors. In 2006, it was renamed the $18 \mathrm{kDa}$ 'Translocator Protein' (TSPO) reflecting its putative function in protein or ligand transport/translocation [9].

Later, it was determined that such receptors are also found in the CNS. It has been shown that such receptors are also commonly found in immune system organs and cells. It has been suggested that these receptor ligands are effective in modulating monocyte functions such as chemotaxis and lymphoid cell proliferation [14]. These findings suggest that TSPOs may play a role in immune/inflammatory events and therefore have the potential to be used as protective agents in reactions such as tissue damage or inflammation. Apart from their common clinical use, benzodiazepines are able to modulate immune functions with their peripheral effects. Selective TSPO agonist Ro5-4684 significantly reduced inflammation mediators such as IL-2 from monocytes [37] and IL-1, TNF- $\alpha$, IL- 6 and reactive oxygen products from macrophages [38]. It has been also shown that it significantly reduces the production of reactive oxygen products, has a protective effect in paw edema caused by carrageenan, and has anti-inflammatory effects [39].

Similarly, it has been shown that Ro5-4684 reduces the severity of rheumatoid arthritis, prevents the migration of inflammatory cells into the joint space in chronic treatment, and has a protective effect against cartilage and bone destruction [40]. TSPOs have also been shown to play a role in cell proliferation and differentiation observed in breast cancer and glioma cells [41]. It has been shown that TSPO ligands can exert an antiapoptotic effect in pathologies in which oxidative stress develops, such as ischemia-reperfusion injury, and are protective against oxidative stress and ischemia-reperfusion injury in the heart [42]. Similarly, TSPOs are associated with different pathological conditions including ischemia-reperfusion injury [43,44], brain injury $[45,46]$, certain forms of epilepsy [44-46], neurodegenerative disorders, Alzheimer's [45,46]and Parkinson's [46] diseases and peripheral neuropathy [47]. We have recently found that Ro5-4864 could be effective in reducing epidural fibrosis in an experimental study model (post-laminectomy) in rats [10].

Farges et al. reported that Ro5-4864 decreased myeloperoxidase and adenosine-deaminase activities and inhibited NO generation in carrageenan-induced pleurisy and its anti-inflammatory properties are modulated by glucocorticoids [48]. In addition, Torres et al. showed that Ro5-4864 inhibited IL-6 in a pleurisy model [49]. Previous investigators have shown 
that TSPO ligands have a significant therapeutic effect and reduce inflammatory pulmonary responses and human lupus erythematosus-like alveolitis in mice [50]. Matsumoto et al. reported that TSPO ligands suppressed LPS-induced TNF activity in mice [51]. The TSPO agonist Ro5-4684, which we used in our study, provided statistically significant reduction and protection in pulmonary edema ( $2 \mathrm{mg} / \mathrm{kg}$ dose) and effusion (at 2 and $4 \mathrm{mg} /$ $\mathrm{kg}$ doses) induced by ANTU. Similarly, it also reduced ANTUmediated intense and widespread leukocyte infiltration (at 2 and $4 \mathrm{mg} / \mathrm{kg}$ doses) and intra alveolar hemorrhage (at $2 \mathrm{mg} / \mathrm{kg}$ ).

Considering that an intense inflammation event continues in ANTU-mediated tissue damage, it is thought that Ro5-4684 may also have anti-inflammatory activity. In our recent studies, it has been shown that the L-arginine/NO pathway plays a role in ANTUmediated ARDS and that iNOS expression increases in lung tissue [21] and both pleural effusion and pulmonary edema decrease in a dose-dependent manner with the use of NO synthase inhibitor, NG-nitro-L-arginine methyl ester (L-NAME). These findings show that the L-arginine/NO pathway plays a role in ANTU-mediated ARDS and NO acts as a cytotoxic molecule [21]. In our current study, an increase in iNOS expression was observed in the lung tissue of ANTU group, and it was determined that the expression decreased with the usage of Ro5-4684, but these changes were not statistically significant. Similarly, Li et al. showed that midazolam significantly reduced expression of iNOS in liver damage induced by lipopolysaccharide [52].

As supported by the literature and our previous study, results shows that benzodiazepine receptors may have an effect on iNOS expression and thus may play a role in tissue damage. In our study, it was determined that TNF- $\alpha$ expression increased significantly in acute lung injury caused by ANTU, and Ro54864 reduced this increase in both doses but this decrease was more at $2 \mathrm{mg} / \mathrm{kg}$ dose. TNF- $\alpha$ is a cytokine secreted by many cell types and an important endogenous mediator, which plays a role in events such as proliferation, apoptosis, morphogenetic changes and differentiation, especially pro-inflammatory activity. As it is known, in the inflammation, apoptosis and thrombosis observed in the pathogenesis of ARDS, TNF- $\alpha$, IL-1, IL- 6 and IL- 8 (proinflammatory cytokines) are secreted [53,54]. Our results show that TNF- $\alpha$ mediated extrinsic apoptosis pathway may be activated in ANTU-mediated tissue damage and Ro5-4864 can prevent this activation.

In this case, since the activation of the extrinsic pathway mediated by TNF- $\alpha$ is known to activate the caspase 8-mediated intrinsic pathway, it will be possible to say that there is an increase in apoptotic activation in both pathways. Following this, these cells are activated by the intense accumulation of neutrophils in the lungs, and as a result, capillary endothelial and alveolar epithelial destruction occurs with the secretion of toxic mediators such as reactive oxygen derivatives and proteases $[55,56]$. The fact that TNF- $\alpha$ level, which is increased by ANTU, can be reduced by Ro5-4864 shows that TSPOs provide protective activity through an important mediator in the damage mechanism. TNF- $\alpha$ is also known to increase iNOS expression. In our study, it was determined that both TNF- $\alpha$ and iNOS expression increased in ANTU-mediated damage, and Ro5-4864 had a suppressive effect on both expressions.

Chemokines are important indicators of inflammation and constitute a large family of polypeptides that have been suggested to be associated with inflammation and tissue damage. MCP-1, one of the chemokines, is encoded by the CCL2 gene. It is thought that MCP-1 plays a role in mononuclear cell activation and bringing it to the inflammation site, cytokine synthesis and inflammatory process, and is effective in the initiation of tissue damage [57]. In our study, serum MCP-1 levels increased significantly in ANTUmediated lung injury compared to the control, and Ro5-4864 decreased this increase in a statistically significant way at 2 and $4 \mathrm{mg} / \mathrm{kg}$ doses.

In our study, the results of flow cytometry were predominantly in the direction of necrosis. A significant rate of necrosis was observed in the ANTU group, and Ro5-4864 showed significant protection against this condition at the doses of 2 and $4 \mathrm{mg} / \mathrm{kg}$. When all data are evaluated, it can be observed that there is a change in the direction of necrosis in the cells in ANTU-mediated damage and at the same time, apoptotic mechanisms are triggered.

\section{Conclusion}

Considering all results, it is seen that TSPOs in the lung tissue can play a role in the pathophysiological mechanisms of ANTU-mediated ARDS and selective peripheral benzodiazepine receptor agonist Ro5-4864 displayed a protective effect on lung tissue damage and effusion development caused by ANTU. Our results corroborate earlier findings concerning the protective effects of Ro5 4864 on lung injury. These results suggest that TSPO agonists to be a novel therapeutic target in lung diseases, including ARDS, and may reduce mortality in intensive care patients. The exact mechanisms of the effects of Ro5-4864 on pulmonary pathophysiology are important and currently not fully understood. The subject is being researched in our laboratories.

\section{Acknowledgements}

We thank Hasan Tahsin Yilmaz and Bayram Cakan for their assistance in research laboratory. The authors would like to thank Dr. E. Schilliger, Schering AG, Berlin, Germany, for his gift of $\alpha$-Naphthylthiourea (Interchim).

\section{References}

1. Ashbaugh DG, Bigelow DB, Petty TL, Levine BE (1967) Acute respiratory distress in adults. Lancet 2(7511): 319-323.

2. Flick MR (1994) Pulmonary edema and acute lung injury. In: Murray JF, Nadel JA, Murray \& Nadel's Textbook of Respiratory Medicine. (2), WB Saunders Company, Philadelphia, USA, Pp: 1725-1777.

3. Mizuta K, Xu D, Pan Y, Comas G, Sonett JR et al. (2008) GABAA receptors are expressed and facilitate relaxation in airway smooth muscle. Am J Physiol Lung Cell Mol Physiol 294(6): L1206-1216. 
4. Papadopoulos V, Baraldi M, Guilarte TR, Knudsen TB, Lacapère JJ, et al. (2006) Translocator protein $(18 \mathrm{kDa})$ : new nomenclature for the peripheral-type benzodiazepine receptor based on its structure and molecular function. Trends Pharmacol Sci 27(8): 402-409.

5. Braestrup C, Squires RF (1977) Specific benzodiazepine receptors in rat brain characterized by high-affinity $(3 \mathrm{H})$ diazepam binding. Proc Natl Acad Sci USA 74(9): 3805-3809.

6. Krueger KE (1995) Molecular and functional properties of mitochondrial benzodiazepine receptors. Biochim Biophys Acta 1241(3): 453-470.

7. Veenman L, Gavish M (2006) The peripheral-type benzodiazepine receptor and the cardiovascular system. Implications for drug development. Pharmacol Ther 110(3): 503-524.

8. Weizman R, Gavish M (1993) Molecular cellular and behavioral aspects of peripheral-type benzodiazepine receptors. Clin Neuropharmacol 16(5): 401-417.

9. Bonsack F, Sukumari-Ramesh S (2018) TSPO: An Evolutionarily Conserved Protein with Elusive Functions. Int J Mol Sci 19(6): 1694.

10. Keskin E, Can EY, Aydin HA, Işik E, Ozgen U, et al. (2021) The preventative effect of of Ro5-4864 (peripheral benzodiazepine receptor agonist) on spinal epidural fibrosis after laminectomy in a rat model. Neurol Res 31: 1-9.

11. Torre D, Minoja G, Maraggia D, Chiaranda M, Tambini R, et al. (1994) Effect of recombinant IL-1 beta and recombinant gamma interferon on septic acute lung injury in mice. Chest 105(4): 1241-1245.

12. Calikoglu M, Tamer L, Sucu N, Coskun B, Ercan B, et al. (2003) The effects of caffeic acid phenethyl ester on tissue damage in lung after hindlimb ischemia-reperfusion. Pharmacol Res 48(4): 397-403.

13. Canat X, Carayon P, Bouaboula M, Cahard D, Shire D, et al. (1993) Distribution profile and properties of peripheral-type benzodiazepine receptors on human hemopoietic cells. Life Sci 52(1): 107-118.

14. Torres SR, Nardi GM, Ferrara P, Ribeiro-do-Valle RM, Farges RC (1999) Potential role of peripheral benzodiazepine receptors in inflammatory responses. Eur J Pharmacol 385(2-3): R1-2.

15. Dushianthan A, Grocott MP, Postle AD, Cusack R (2011) Acute respiratory distress syndrome and acute lung injury. Postgrad Med J 87(1031): 612-622.

16. Matthay MA, Zimmerman GA, Esmon C, Bhattacharya J, Coller B, et al. (2003) Future research directions in acute lung injury: summary of a National Heart, Lung, and Blood Institute working group. Am J Respir Crit Care Med 167(7): 1027-1035.

17. Piantadosi CA, Schwartz DA (2004) The acute respiratory distress syndrome. Ann Intern Med 141(6): 460-470.

18. Tsushima K, King LS, Aggarwal NR, De Gorordo A, D’Alessio FR, et al. (2009) Acute lung injury review. Intern Med 48(9): 621-630.

19. Puneet P, Moochhala S, Bhatia M (2005) Chemokines in acute respiratory distress syndrome. Am J Physiol Lung Cell Mol Physiol 288(1): L3-15.

20. Jain R, DalNogare A (2006) Pharmacological therapy for acute respiratory distress syndrome. Mayo Clin Proc 81(2): 205-212.

21. Sipahi E, Hodoglugil U, Ustun H, Zengil H, Turker RK, et al. (1997) An unexpected interaction between NG-nitro-L-arginine methyl ester and L-arginine in alpha-naphthylthiourea-induced pulmonary oedema in rats. Eur J Pharmacol 321(1): 45-51.

22. Bernard GR, Artigas A, Brigham KL, Carlet J, Falke K, et al. (1994) Report of the American-European consensus conference on ARDS: definitions, mechanisms, relevant outcomes and clinical trial coordination. The Consensus Committee. Intensive Care Med 20(3): 225-232.
23. Cunningham AL, Hurley JV (1972) Alpha-naphthyl-thiourea-induced pulmonary oedema in the rat: a topographical and electron-microscope study. J Pathol 106(1): 25-35.

24. Minty BD, Scudder CM, Grantham CJ, Jones JG, Bakhle YS (1987) Sequential changes in lung metabolism, permeability, and edema after ANTU. J Appl Physiol 62(2): 491-496.

25. Scott AM, Powell GM, Upshall DG, Curtis CG (1990) Pulmonary toxicity of thioureas in the rat. Environ Health Perspect 85: 43-50.

26. Sipahi E, Hodoglugil U, Ercan ZS, Turker RK (1996) Acute effect of endothelin-1 on lung oedema induced by alpha-naphthylthiourea (ANTU). Pharmacol Res 33(6): 375-378.

27. O’Brien RF, Makarski JS, Rounds S (1985) Studies on the mechanism of decreased angiotensin I conversion in rat lungs injured with alphanaphthylthiourea. Exp Lung Res 8(4): 243-259.

28. Ercan ZS, Eren S, Zengil H, Turker RK (1993) Possible involvement of eicosanoids in alpha-naphthylthiourea-induced pulmonary oedema and alteration of angiotensin-converting enzyme activity. Pharmacology 46(5): 274-280.

29. Sipahi EY, Ozel Tekin I, Comert M, Barut F, Ustun H, et al. (2004) Oxidized low-density lipoproteins accumulate in rat lung after experimental lung edema induced by alpha- naphthylthiourea (ANTU). Pharmacol Res 50(6): 585-591.

30. Comert M, Sipahi EY, Ustun H, Isikdemir F, Numanoglu G, et al. (2005) Morphine modulates inducible nitric oxide synthase expression and reduces pulmonary oedema induced by alpha-naphthylthiourea. Eur J Pharmacol 511(2-3): 183-189.

31. Pankhania JJ, Bakhle YS (1985) Effect of pulmonary oedema induced by alpha-naphthylthiourea on synthesis of cyclo-oxygenase products in rat isolated lungs. Prostaglandins 30(1): 37-49.

32. Hardwick SJ, Skamarauskas JT, Smith LL, Upshall DG, Cohen GM (1991) Protection of rats against the effects of alpha-naphthylthiourea (ANTU) by elevation of non-protein sulphydryl levels. Biochem Pharmacol 42(6): 1203-1208.

33. Sipahi EY, Ozel Tekin I, Comert M, Barut F, Ustun H, et al. (2004) Oxidized low-density lipoproteins accumulate in rat lung after experimental lung edema induced by alpha- naphthylthiourea (ANTU). Pharmacol Res 50(6): 585-591.

34. Sipahi E, Ustün H, Niyazi Ayoglu F (2002) Acute effects of pentobarbital, thiopental and urethane on lung oedema induced by alphanaphthythiourea (ANTU). Pharmacol Res 45(3): 235-239.

35. Hanci V, Yurdakan G, Yurtlu S, Turan IO, Sipahi EY (2012) Protective effect of dexmedetomidine in a rat model of $\alpha$-naphthylthioureainduced acute lung injury. J Surg Res 178(1): 424-430.

36. Kaynar G, Yurdakan G, Comert F, Yilmaz-Sipahi E (2013) Effects of peripheral benzodiazepine receptor ligand Ro5-4864 in four animal models of acute lung injury. J Surg Res 182(2): 277-84.

37. Bessler H, Weizman R, Gavish M, Notti I, Djaldetti M (1992) Immunomodulatory effect of peripheral benzodiazepine receptor ligands on human mononuclear cells. J Neuroimmunol 38(1-2): 19-25.

38. Zavala F, Taupin V, Descamps-Latscha B (1990) In vivo treatment with benzodiazepines inhibits murine phagocyte oxidative metabolism and production of interleukin 1, tumor necrosis factor and interleukin-6. J Pharmacol Exp Ther 255(2): 442-450.

39. Matute-Bello G, Liles WC, Radella F 2nd, Steinberg KP, Ruzinski JT, et al. (2000) Modulation of neutrophil apoptosis by granulocyte colonystimulating factor and granulocyte/macrophage colony-stimulating factor during the course of acute respiratory distress syndrome. Crit Care Med 28(1): 1-7. 
40. Elmore S (2007) Apoptosis: a review of programmed cell death. Toxicol Pathol 35(4): 495-516.

41. Suda T, Nagata S (1994) Purification and characterization of the Fasligand that induces apoptosis. J Exp Med 179(3): 873-879.

42. Spierings DC, de Vries EG, Vellenga E, vanden Heuvel FA, Koornstra JJ, et al. (2004) Tissue distribution of the death ligand TRAIL and its receptors. J Histochem Cytochem 52(6): 821-831.

43. Hauet T, Han Z, Wang Y, Hameury F, Jayle C, et al. (2002) Modulation of peripheral-type benzodiazepine receptor levels in a reperfusion injury pig kidney-graft model. Transplantation 74(11): 1507-1515.

44. Ducis I, Norenberg LO, Norenberg MD (1990) The benzodiazepine receptor in cultured astrocytes from genetically epilepsy-prone rats. Brain Res 531(1-2): 318-321.

45. Gavish M, Bachman I, Shoukrun R, Katz Y, Veenman L, et al. (1999) Enigma of the peripheral benzodiazepine receptor. Pharmacol Rev 51(4): 629-650.

46. Papadopoulos V, Lecanu L, Brown RC, Han Z, Yao ZX (2006) Peripheraltype benzodiazepine receptor in neurosteroid biosynthesis, neuropathology and neurological disorders. Neuroscience 138(3): 749-756.

47. Leonelli E, Yague JG, Ballabio M, Azcoitia I, Magnaghi V, et al. (2005) Ro5-4864, a synthetic ligand of peripheral benzodiazepine receptor, reduces aging-associated myelin degeneration in the sciatic nerve of male rats. Mech Ageing Dev 126(11): 1159-1163.

48. Farges RC, da Silva MB, Frode TS (2006) Implication of glucocorticoid in anti-inflammatory effects of Ro5-4864 in mouse pleurisy induced by carrageenan. Life Sci 78(16): 1814-1822.

49. Torres SR, Frode TS, Nardi GM, Vita N, Reeb R, et al. (2000) Anti- inflammatory effects of peripheral benzodiazepine receptor ligands in two mouse models of inflammation. Eur J Pharmacol 408(2): 199-211.

50. Bribes E, Bourrie B, Casellas P (2003) Ligands of the peripheral benzodiazepine receptor have therapeutic effects in pneumopathies in vivo. Immunol Lett 88(3): 241-247.

51. Matsumoto T, Ogata M, Koga K, Shigematsu A (1994) Effect of peripheral benzodiazepine receptor ligands on lipopolysaccharideinduced tumor necrosis factor activity in thioglycolate-treated mice. Antimicrob Agents Chemother 38(4): 812-816.

52. Li J, Tan H, Zhou X, Zhang C, Jin H, et al. (2019) The Protection of Midazolam Against Immune Mediated Liver Injury Induced by Lipopolysaccharide and Galactosamine in Mice. Front Pharmacol 9: 1528.

53. Parsons PE, Eisner MD, Thompson BT, Matthay MA, Ancukiewicz M, et al. (2005) Lower tidal volume ventilation and plasma cytokine markers of inflammation in patients with acute lung injury. Crit Care Med 33(1): 1-6.

54. Chollet-Martin S, Gatecel C, Kermarrec N, Gougerot-Pocidalo MA Payen DM (1996) Alveolar neutrophil functions and cytokine levels in patients with the adult respiratory distress syndrome during nitric oxide inhalation. Am J Respir Crit Care Med 153(3): 985-990.

55. Ware LB, Matthay MA (2000) The acute respiratory distress syndrome. N Engl J Med 342(18): 1334-1349.

56. Gadek JE, Pacht ER (1996) The interdependence of lung antioxidants and antiprotease defense in ARDS. Chest 110(6 Suppl): 273S-277S

57.Zhao H, Chen H, Xiaoyin M, Yang G, Hu et al. (2019) Autophagy Activation Improves Lung Injury and Inflammation in Sepsis. Inflammation 42(2): 426-439.

Your next submission with Juniper Publishers
will reach you the below assets
- Quality Editorial service
- Swift Peer Review
- Reprints availability
- E-prints Service
- Manuscript Podcast for convenient understanding
- Global attainment for your research
- Manuscript accessibility in different formats
( Pdf, E-pub, Full Text, Audio)
- Unceasing customer service
Track the below URL for one-step submission
https://juniperpublishers.com/online-submission.php

